\title{
A Comprehensive Meta-analysis on Evidence of Mediterranean Diet and Cardiovascular Disease: Are Individual Components Equal?
}

\section{Citation}

Grosso, Giuseppe, Stefano Marventano, Justin Yang, Agnieszka Micek, Andrzej Pajak, Luca Scalfi, Fabio Galvano, and Stefanos N. Kales. 2015. "A Comprehensive MetaAnalysis on Evidence of Mediterranean Diet and Cardiovascular Disease: Are Individual Components Equal?" Critical Reviews in Food Science and Nutrition (November 3): 00-00. doi:10.1080/10408398.2015.1107021.

\section{Published Version}

10.1080/10408398.2015.1107021

\section{Permanent link}

http://nrs.harvard.edu/urn-3:HUL.InstRepos:37140306

\section{Terms of Use}

This article was downloaded from Harvard University's DASH repository, and is made available under the terms and conditions applicable to Other Posted Material, as set forth at http:// nrs.harvard.edu/urn-3:HUL.InstRepos:dash.current.terms-of-use\#LAA

\section{Share Your Story}

The Harvard community has made this article openly available.

Please share how this access benefits you. Submit a story.

Accessibility 


\title{
A comprehensive meta-analysis on evidence of Mediterranean diet and cardiovascular
}

\section{disease: are individual components equal?}

\author{
Giuseppe Grosso ${ }^{a}$, Stefano Marventano ${ }^{b}, J_{u s t i n}$ Yang $^{\mathrm{c}, \mathrm{d}}$, Agnieszka Micek $^{\mathrm{e}}$, Andrzej Pajak $^{\mathrm{e}}$, Luca Scalfi ${ }^{\mathrm{f}}$, Fabio \\ Galvano $^{\mathrm{g}}$, Stefanos N. Kales ${ }^{\mathrm{c}, \mathrm{h}}$ \\ antegrated Cancer Registry of Catania-Messina-Siracusa-Enna, Catania, Italy \\ ${ }^{b}$ Department of Medical, Surgical Sciences, and Advanced Technologies “G.F. Ingrassia”, Section of Hygiene and \\ Preventive Medicine, University of Catania, Catania, Italy \\ ${ }^{c}$ Department of Environmental Health, Environmental \& Occupational Medicine \& Epidemiology, Harvard TH Chan \\ School of Public Health, Boston, Massachusetts, United States of America \\ ${ }^{d}$ St Elizabeth's Medical Center, Tufts University School of Medicine, Boston, Massachusetts, United States of America \\ ${ }^{e}$ Department of Epidemiology and Population Studies, Jagiellonian University Medical College, Krakow, Poland \\ ${ }^{f}$ Department of Food Science, "Federico II" University Medical School, Naples, Italy \\ ${ }^{g}$ Department of Biomedical and Biotechnological Sciences, Section of Pharmacology and Biochemistry, University of \\ Catania, Catania, Italy \\ ${ }^{f}$ The Cambridge Health Alliance, Harvard Medical School, Cambridge, Massachusetts, United States of America
}

Corresponding author:

Giuseppe Grosso, MD, PhD,

Integrated Cancer Registry of Catania-Messina-Siracusa-Enna,

Via S. Sofia 85, 95123 Catania, Italy.

Phone: +390953782182

Fax: +390953782177

Email: giuseppe.grosso@studium.unict.it

\begin{abstract}
Many studies have reported that higher adherence to Mediterranean diet may decrease cardiovascular disease (CVD) incidence and mortality. We performed a metaanalysis to explore the association in prospective studies and randomized control trials (RCTs) between Mediterranean diet adherence and CVD incidence and mortality. The PubMed database was searched up to June 2014. A total of 17 studies were extracted and 11 qualified for the quantitative analysis. Individuals in the highest quantile of adherence to the diet had lower incidence (Relative Risk [RR]: 0.76, 95\% confidence intervals [CI]: $0.68,0.83$ ) and mortality (RR: $0.76,95 \%$ CI: $0.68,0.83$ ) from CVD compared to those least adherent. A significant reduction of risk was found also for coronary heart disease (RR: $0.72,95 \%$ CI: $0.60,0.86$ ), myocardial infarction (RR: 0.67 ; 95\% CI: $0.54,0.83$ ), and stroke (RR: $0.76 ; 95 \%$ CI: $0.60,0.96$ ) incidence. Pooled analyses of individual components of the diet revealed that the protective effects of the diet appear to be most attributable to olive oil, fruits, vegetables, and legumes. An average reduced risk of $40 \%$ for the aforementioned outcomes has been retrieved when pooling results of RCTs. A Mediterranean dietary pattern is associated with lower risks of CVD incidence and mortality, including CHD and MI. The relative effects of specific food groups should be further investigated.
\end{abstract}

Keywords
Prevention; randomized controlled trials; prospective cohort studies; olive oil; vegetables; fruit; legumes.

\section{Introduction}

Cardiovascular disease (CVD) is a major public health issue worldwide and the leading cause of morbidity and mortality in the western world (Capewell and Buchan 2012). The rising prevalence of cardio-metabolic conditions, such as obesity, hypertension, and diabetes is considered a prominent cause of this increasing trend (Capewell and Buchan 2012). Dietary and lifestyle factors are among the most important determinants of these metabolic risk factors (Capewell and Buchan 2012). Based on epidemiological and experimental studies, it has been suggested that certain types of diet rich in whole grain cereals, fruit and vegetables, and low in animal fats may have beneficial cardio-protective effects (Buscemi et al., 2013; Grosso et al., 2014a; Grosso et al., 2014b; Yang et al., 2014). Among them, the geographical difference in CVD incidence and mortality observed in the $60 \mathrm{~s}$ in favor of Southern European population led to the hypothesis that a Mediterranean dietary pattern was protecting against CVD, lately supported by the strongest evidence relating its beneficial effects on coronary heart disease (CHD) risk (Mente et al., 2009). Some of the most common features of Mediterranean diet are represented by i) consumption of a large quantity of plant-derived foods (fruit, vegetables, and legumes), cereals (especially whole-grains) and fish; ii) low 
intake of meat and dairy products; iii) daily intake of olive oil and nuts, and iv) moderate intake of wine (especially red wine) during meals (Estruch and Salas-Salvado 2013). According to such characteristics, this plant-rich diet may provide benefits through the high content of antioxidants and fiber, with fish, nuts and olive oil that ensure a high intake of polyunsaturated fatty acids (PUFA) and monounsaturated fatty acids (MUFA), associated with a low intake of saturated and trans-fatty acids from meat and sweets (Estruch and Salas-Salvado 2013). Besides the several indexes and scores that have been developed to assess adherence to the Mediterranean dietary pattern (Bach et al., 2006), the main issue on what really differentiate such diet from other pattern found to be similarly protective against CHD (such as "prudent" diets, equally rich in anti-oxidant phytochemicals and similar lipid profiles) is still an open debate (Mente et al., 2009). Approaches aimed to individualize whether the protective effects depend on single foods or nutrients seem to conclude that the efficacy of Mediterranean diet should be considered as relying on the whole diet including each of its components. Nevertheless, there is no single definition for this traditional dietary pattern because the variety of foods specifically consumed among and within countries makes the Mediterranean diet extremely heterogeneous and strongly influenced by food availability and cultural heritage differences by geographical regions.

A number of studies reported that individuals more adherent to this dietary pattern have a significantly decreased risk in CVD incidence and mortality (Sofi et al., 2013). Furthermore, adherence to Mediterranean diet has been associated with better survival after an established diagnosis of CVD (Kastorini et al., 2010). Previous quantitative metaanalyses of prospective cohort studies pooling fatal and nonfatal CVD events together reported a decreased risk of $10 \%$ for a 2-point increase in Mediterranean diet adherence score, but analyses for specific outcomes, such as the risk of CHD, myocardial infarction (MI), and stroke, are lacking. Moreover, the actual meta-analyses refer only to studies using a specific dietary index and relied only on observational studies (Sofi et al., 2013). Overall, it would be of interest to evaluate findings from both observational and experimental studies with specific CVD outcomes by considering the adherence to the Mediterranean diet irrespectively of the score used, rather focusing on the highest level of adherence possible, in line with the corroborated idea that benefits of this dietary pattern depend on each of its main features. Nevertheless, the impact of its single components in the context of Mediterranean diet has never been evaluated in pooled analyses and could be taken into account to provide insights of their effective role in protecting against CVD.

The aim of this study was to systematically review and compare results from prospective investigations and randomized controlled trials (RCTs) exploring the effectiveness of Mediterranean diet in reducing CVD incidence and mortality. This is the first meta-analysis designed to evaluate the effects of high adherence to the diet on specific outcomes, such as CHD, MI, and stroke, with no restriction on the adherence score used in any component study. We also explored whether individual components of Mediterranean diet, being evaluated in its context, were significantly related with any CVD related outcome.

\section{Methods}

\section{Search strategy and study selection}

Literature databases including PubMed, SCOPUS, and EMBASE were searched from January 2000 through June 2014. Relevant keywords relating to Mediterranean diet ("Mediterranean diet") were searched in combination with keywords relating to cardiovascular events ("cardiovascular disease" or "cardiovascular event" or "myocardial infarction" or "coronary heart disease" or "coronary artery disease" or "ischemic heart disease" or "angina" or "stroke" or "cerebrovascular disease"), and in combination with keywords relevant to the study methods ("incidence" or "cohort" or "follow-up" or "trial" or "hazard ratio" or "odds ratio" or "relative risk" or "rate ratio"). Reference lists of retrieved articles were manually searched by two researchers (GG and SM). The literature search was limited to English. If more than one article was published using the same cohort, the most recent article with the longest follow-up period was considered. Studies included in this systematic review met all of the following inclusion criteria: i) evaluated the risk or association between Mediterranean diet adherence, CVD incidence and/or mortality (including CHD, MI, and stroke) with a prospective or RCT design; ii) used an a priori method to evaluate adherence to the diet; iii) clearly defined the intervention diet as "Mediterranean" and described its characteristics (only RCTs). The two investigators independently assessed articles for compliance with the inclusion and exclusion criteria and resolved disagreements through consensus.

In total, 230 studies that evaluated the effect of Mediterranean diet on the outcomes of interest were identified. The full process of identification and selection of studies is shown in Figure 1. The relevance of studies was assessed with a hierarchical approach on the basis of title, abstract, and the full manuscript. Of the 47 studies considered relevant as prospective, 29 were excluded for the following reasons: 15 studies had different design; 7 studies evaluated non CVD outcomes; 3 studies defined the Mediterranean dietary pattern through principal component analysis (PCA); 2 studies had reported longer follow-up in updated reports; 1 study reported insufficient statistics; 1 study was conducted on a subgroup of an entire cohort already included. Of the 13 studies considered relevant as RCTs, 9 were excluded for the following reasons: 3 had different design; 2 did not sufficiently specify the intervention as "Mediterranean"; 2 were duplicate publications; 1 had reported longer follow-up in updated reports; 1 study reported insufficient statistics. Overall, 20 prospective studies (Knoops et al., 2004; Mitrou et al., 2007; Panagiotakos et al., 2008; Buckland et al., 2009; Fung et al., 2009; Chrysohoou et al., 2010; Agnoli et al., 2011; Buckland et al., 2011; Gardener et al., 2011; Hodge et al., 2011; Martinez-Gonzalez et al., 2011; Dilis et al., 2012; Hoevenaar-Blom et al., 2012; Menotti et al., 2012; Misirli et al., 2012; Tognon et al., 2012; Hoevenaar-Blom et al., 2013; Tognon et al., 2013; Bertoia et al., 2014; Lopez-Garcia et al., 2014) and 4 RCTs (de Lorgeril et al., 1999; Singh et al., 2002; Giannuzzi et al., 2008; Estruch et al., 2013) were included in this systematic review and meta-analysis.

\section{Data extraction}

The following information was extracted from each study: i) name of the first author; ii) year of publication; iii) study cohort or name; iv) country; v) number of participants; vi) gender of participants; vii) age range or mean age of the study population at baseline; viii) follow-up period; ix) 
endpoints and cases; $\mathrm{x}$ ) diet adherence score used; $x i)$ RRs or HRs with $95 \%$ CIs for high adherence categories of exposure; and xii) covariates used in adjustments. Regarding RCTs, description of intervention and controls was also evaluated.

The quality of observational studies was assessed according to the Newcastle-Ottawa quality assessment Scale (Wells et al., 1999), consisting of three parameters of quality: selection (four points), comparability (two points), and outcome (three points), with a score of seven or more points reflecting high quality. Study quality of RCTs was measured according the Jadad criteria (Jadad et al., 1996).

\section{Exposure and outcome measures}

Adherence to a Mediterranean diet was defined through scores that estimated dietary pattern conformity of the studied population with traditional Mediterranean dietary pattern. Overall, people more adherent to the Mediterranean diet were considered those included in the highest quantile of the score used in each study. In studies where point scale system was utilized instead of quantiles, we transformed HR by calculating differences between upper half score individuals versus lower half score individuals.

CVD events comprised cases of myocardial infarction/acute coronary syndromes (MI), stroke, and/or CHD, when present. CVD mortality was defined as fatal events related with cardiovascular system according to definitions provided in each study.

\section{Statistical analysis}

RRs or HRs with $95 \%$ CIs for all categories of exposure were extracted for the analysis and random-effects models were used to calculate pooled RRs with $95 \%$ CIs for highest compared with lowest category of exposure (i.e., highest vs. lowest quantile of adherence to Mediterranean diet). Heterogeneity was assessed by using the $Q$ test and $\mathrm{I}^{2}$ statistic. The significance for the $\mathrm{Q}$ test was defined as $P$ $<0.10$. The $I^{2}$ statistic represents the amount of total variation that could be attributed to heterogeneity. $I^{2}$ values $\leq 25 \%$, $\leq 50 \%, \leq 75 \%$ and $>75 \%$ indicated no, little, moderate, and significant heterogeneity, respectively. Meta-regression analyses for number of participants, number of cases, year of publication, geographical location, and duration of follow-up were performed to identify source of heterogeneity. A sensitivity analysis was conducted by excluding one study at a time was performed to assess the stability of results. Subgroup analyses were conducted by geographical region (Mediterranean and non-Mediterranean countries), duration of follow-up ( $\leq 10$ and $>10$ years), sample size $(\leq 10,000$ and $>10,000$ participants), and method of Mediterranean diet adherence assessment (modified Mediterranean diet score [mMed score] and others). Publication bias was assessed by visual observation of funnel plot. All analyses were performed with Review Manager (RevMan) version 5.2 (Copenhagen: The Nordic Cochrane Centre, The Cochrane Collaboration).

\section{Results}

\section{Prospective studies on Mediterranean diet}

The major characteristics of the 20 studies included in this systematic review are presented in Table 1 (Knoops et al.,
2004; Mitrou et al., 2007; Panagiotakos et al., 2008; Buckland et al., 2009; Fung et al., 2009; Chrysohoou et al., 2010; Agnoli et al., 2011; Buckland et al., 2011; Gardener et al., 2011; Hodge et al., 2011; Martinez-Gonzalez et al., 2011; Dilis et al., 2012; Hoevenaar-Blom et al., 2012; Menotti et al., 2012; Misirli et al., 2012; Tognon et al., 2012; Hoevenaar-Blom et al., 2013; Tognon et al., 2013; Bertoia et al., 2014; Lopez-Garcia et al., 2014). In total, there were 888,257 participants with 22,987 cumulative incident cases of CVD (including deaths). Most studies comprised individuals of age ranging from 20 to 70 years old, while 3 studies (Knoops et al., 2004; Dilis et al., 2012; Misirli et al., 2012) were conducted solely on elderly participants ( $>70$ years old). Two studies evaluated the prevalence of CVD at follow-up visit, hence reporting ORs (Panagiotakos et al., 2008; Chrysohoou et al., 2010). Three studies explored Mediterranean diet adherence in patients at high CVD risk, two of them including individuals with previous CVD incidents (Chrysohoou et al., 2010; Lopez-Garcia et al., 2014) and one was conducted on diabetic individuals (Hodge et al., 2011). All studies included covariates that are considered to have significant influence on cardiovascular outcomes such as age, gender (when not analyzed separately), BMI, education, physical activity, and smoking status. The comprehensive groups of covariates used for adjustments are described in Table 1 .

Thirteen studies (Panagiotakos et al., 2008; Buckland et al., 2009; Fung et al., 2009; Chrysohoou et al., 2010; Agnoli et al., 2011; Gardener et al., 2011; Martinez-Gonzalez et al., 2011; Dilis et al., 2012; Hoevenaar-Blom et al., 2012; Menotti et al., 2012; Misirli et al., 2012; Hoevenaar-Blom et al., 2013; Tognon et al., 2013) accounting for 13,434 CVD events [6 studies (Chrysohoou et al., 2010; Agnoli et al., 2011; Martinez-Gonzalez et al., 2011; Dilis et al., 2012; Misirli et al., 2012; Hoevenaar-Blom et al., 2013) included composite incidence and mortality cases] were pooled together to estimate the risk of CVD incidence as a function of Mediterranean diet adherence. High Mediterranean diet adherence was inversely associated with decreased risk of CVD incidence (RR: $0.73,95 \%$ CI: $0.66,0.80$ ) compared to lowest adherence (Figure 2), with no significant evidence of heterogeneity $\left(I^{2}=36 \%\right)$. Sensitivity analysis was conducted by removing one study at a time and no significant changes in result were found. No significant evidence of heterogeneity was found at meta-regression analysis. After considering separately those studies accounting for composite incidence and mortality outcome (Chrysohoou et al., 2010; Agnoli et al., 2011; Martinez-Gonzalez et al., 2011; Dilis et al., 2012; Misirli et al., 2012; Hoevenaar-Blom et al., 2013), risk of CVD slightly decreased (RR: $0.66,95 \%$ CI: $0.55,0.80)$ due to the effect of one study (Panagiotakos et al., 2008) responsible also for heterogeneity $\left(I^{2}=72 \%\right)$, which after its exclusion dropped to $36 \%$ and the reported risk estimate remain unchanged.

Thirteen studies (Knoops et al., 2004; Mitrou et al., 2007; Fung et al., 2009; Buckland et al., 2011; Hodge et al., 2011; Dilis et al., 2012; Hoevenaar-Blom et al., 2012; Menotti et al., 2012; Misirli et al., 2012; Tognon et al., 2012; Tognon et al., 2013; Bertoia et al., 2014; Lopez-Garcia et al., 2014) accounting for 9563 cases of death from CVD were pooled together to estimate the risk of CVD mortality as a function of Mediterranean diet adherence. High adherence to the Mediterranean diet was inversely associated with risk of CVD mortality (RR: 0.75 ; 95\% CI: $0.68,0.83$ ) compared to that of the lowest adherence (Figure 2), with significant 
evidence of heterogeneity $\left(I^{2}=75 \%\right)$. Evidence of heterogeneity may be attributed to two studies (Tognon et al., 2012; Tognon et al., 2013) for which HRs were estimated by 1-point score increase for two categories of exposure. However, after exclusion of such studies at sensitivity analysis, risk estimate remained mostly unchanged (RR: 0.73 ; $95 \%$ CI: $0.68,0.79$ ). No further evidence of heterogeneity was found at meta-regression analysis.

A pooled analysis was performed to evaluate as a composite outcome the risk of incidence and/or death from CVD (Figure $2)$, resulting in a cumulative RR of 0.71 (95\% CI: $0.65,0.78)$, with significant evidence of heterogeneity $\left(I^{2}=78 \%\right)$ and slight asymmetry at funnel plot (Supplemental Figure 1). Sensitivity analysis by excluding the studies responsible for asymmetry at funnel plot (Panagiotakos et al., 2008; Chrysohoou et al., 2010; Martinez-Gonzalez et al., 2011) did not change the results (RR: 0.74; 95\% CI: 0.68, 0.80). The analysis was repeated excluding those studies conducted on patients at high risk, which resulted in unchanged risk estimate (RR $0.71,95 \%$ CI $0.63,0.77$ ). Table 2 shows results of subgroup analyses by geographical area, sample size, length of follow-up, and type of Mediterranean adherence score, with no substantial differences between groups.

Regarding specific CVD outcomes, 4 studies examined CHD incidence (Buckland et al., 2009; Fung et al., 2009; MartinezGonzalez et al., 2011; Dilis et al., 2012), 3 studies on MI incidence (Gardener et al., 2011; Hoevenaar-Blom et al., 2012; Tognon et al., 2013) and 5 studies on stroke incidence (Fung et al., 2009; Gardener et al., 2011; Hoevenaar-Blom et al., 2012) (Agnoli et al., 2011; Tognon et al., 2013). High adherence to Mediterranean diet was inversely associated with risk of CHD (RR: $0.72,95 \%$ CI: 0.60, 0.86), MI (RR: 0.67; 95\% CI: 0.54, 0.83), and stroke (RR: 0.76 ; 95\% CI: $0.60,0.96)$, with little evidence of heterogeneity only for stroke outcome $\left(I^{2}=52 \%\right)$ (Figure 3 ). However, no significant source of heterogeneity was found at metaregression and sensitivity analysis.

\section{Food group components of the Mediterranean diet and CVD outcomes}

Scoring systems used in studies assessing the Mediterranean diet adherence are listed in Table 1. Some differences among food groups used in the studies existed, especially in relation to the food category of (i) vegetables, grouped with potatoes in those studies using the mMed score (Knoops et al., 2004; Dilis et al., 2012; Hoevenaar-Blom et al., 2012; Misirli et al., 2012; Tognon et al., 2012; Hoevenaar-Blom et al., 2013; Tognon et al., 2013); (ii) meat and meat products, grouped with poultry in studies using the relative Mediterranean diet score (rMed score) (Buckland et al., 2009; Buckland et al., 2011); and (iii) nuts and seeds, grouped with fruits in some studies (Mitrou et al., 2007; Buckland et al., 2009; Buckland et al., 2011; Martinez-Gonzalez et al., 2011), with legumes in another study (Knoops et al., 2004), and considered a group by themselves in some others (Fung et al., 2009; HoevenaarBlom et al., 2012), irrespectively of the score used.

For individuals considered as highly adherent to the Mediterranean dietary pattern (highest quantile of the score), average daily consumption of specific food groups are summarized in Table 3. Quantitative amounts of individual food groups were highly variable across studies. Generally, higher intakes of fruit, vegetables, and fish were described in Mediterranean cohorts (Buckland et al., 2009; Buckland et al., 2011; Martinez-Gonzalez et al., 2011; Misirli et al., 2012) whereas meat and dairy products were consumed in higher quantities in non-Mediterranean countries (Tognon et al., 2012; Tognon et al., 2013). Pooled risk analysis for single Mediterranean diet food components showed in Figure 4 revealed a significant reduction of CVD risk for adequate olive oil consumption (RR: $0.83 ; 95 \%$ CI: $0.77,0.89 ; I^{2}=$ $0 \%$ ), vegetable intake (RR: $0.87 ; 95 \%$ CI: $0.77,0.98 ; I^{2}=$ $54 \%$ ), fruit (RR: $0.88 ; 95 \%$ CI: $0.81,0.96 ; I^{2}=33 \%$ ), and legumes (RR: $0.91 ; 95 \%$ CI: $0.83,0.98 ; I^{2}=33 \%$ ), and increased risk for dairy products (RR: $1.10 ; 95 \%$ CI: 1.02 , $\left.1.19 ; I^{2}=49 \%\right)$. Non-significant trend toward decreased risk were also found for fish (RR: $0.96 ; 95 \% \mathrm{CI}: 0.91,1.01 ; I^{2}=$ $36 \%$ ), cereals consumption (RR: $0.95 ; 95 \%$ CI: $0.90,1.00 ; I^{2}$ $=0 \%$ ), and alcohol intake (RR: $0.97 ; 95 \%$ CI: $0.88,1.07 ; I^{2}=$ $70 \%$ ), and increased for meat products consumption (RR: 1.02; $95 \%$ CI: $0.96,1.08 ; I^{2}=0 \%$ ). Sensitivity analysis reduced heterogeneity to $0 \%$ for all food components except alcohol with substantially unchanged results; however, neither alcohol, meat products, nor fish intake reached significance.

\section{RCTs on Mediterranean diet}

The main characteristics of the 4 included RCTs are summarized in Table 4 (de Lorgeril et al., 1999; Singh et al., 2002; Giannuzzi et al., 2008; Estruch et al., 2013). A total of 12,293 individuals at high CVD risk (7418 interventions/4874 controls) and 590 composite cases of CVD (including CVD mortality, MI and stroke incidence) were included in the analysis. Interventions among studies differed based on investigators' emphasis on the Mediterranean diet; major focus was given to margarine enriched diet in de Lorgeril et al. (2004), fruit and vegetables in Singh et al. (2002), general advices according to the mMed score in Giannuzzi et al. (2008), and olive oil and nuts in Estruch et al. (2013). Subjects in control groups were given similar dietary advice among studies (Table 3 ).

Overall, all outcomes evaluated agreed with an average $40 \%$ decreased risk of CVD incidence (for MI, RR: 0.60; $95 \%$ CI: $0.44,0.82 ; I^{2}=26 \%$; for stroke, RR: $0.64 ; 95 \%$ CI: 0.47 , $0.86 ; I^{2}=0 \%$; ) and mortality (RR: 0.59 ; $95 \%$ CI: $0.38,0.93$; $I^{2}=46 \%$ ) in the intervention group compared with controls. However, differences between studies in the efficacy of intervention were evident when considering specific outcomes, such as CVD mortality (Singh et al., 2002; de Lorgeril and Salen 2004) and MI incidence (Singh et al., 2002; Giannuzzi et al., 2008), which were significant in studies published earlier in time, or stroke incidence, which was significant only in the PREDIMED study (Estruch et al., 2013). However, when evaluating the composite outcome (provided by all studies), a pooled estimated risk of 0.55 (95\% CI: $0.39,0.76)$ was found with moderate heterogeneity among studies $\left(I^{2}=68 \%\right)$ and no evidence of publication bias at funnel plot. Meta-regression analysis revealed that a significant effect in the final result could be attributed to the year of publication due to a gradient toward lower risk for older studies (data not shown).

\section{Discussion}

To the best of our knowledge, this is the first study to systematically assess, through meta-analysis, the role of Mediterranean diet on CVD incidence and mortality in prospective studies and RCTs, including a specific analysis 
on CHD, MI, and stroke, with no restriction of method in assessing diet adherence. Besides the corroborated idea that adherence to a Mediterranean dietary pattern is protective against CVD, we aimed to quantify this association for individuals highly adherent (identified as those grouped in the highest quantile in each prospective study) and compare it with the risk estimated by experimental studies. The current meta-analysis supports the hypothesis that highly adherent individuals had lower CVD morbidity and mortality with a decreased risk of about $30 \%$ in prospective studies and of about $40-45 \%$ in RCTs conducted on patients with high CVD risk. Such differences in risk reduction observed in intervention studies compared with observational may be due to that the latter were mostly conducted on general populations [with the exception of three studies (Chrysohoou et al., 2010; Hodge et al., 2011; Lopez-Garcia et al., 2014)], whereas RCTs enrolled individuals at high CVD risk, thus maximizing the interventional effects.

When examining specific types of CVD, we found mostly stable estimated risks for $\mathrm{CHD}$, MI, and stroke among different study designs, despite slight heterogeneity was found among prospective studies on stroke incidence. The fact that ischemic stroke could be etiologically heterogeneous may have contributed to the lack of association observed in some studies, whereas results on MI were more uniform as pathological mechanisms of MI are more homogeneous. Likewise, similar issues have been faced when considering RCTs, with a certain grade of discordance regarding potential protection of the Mediterranean diet toward both MI and stroke incidence. Considering the limited number of studies with available information on specific outcomes, further research is needed to clarify whether high Mediterranean diet adherence provides protection against specific cardio- and/or cerebrovascular diseases.

Despite current scientific findings and understandings of the observed cardio-protective effects of Mediterranean-style diet, the full mechanisms and pathways are not completely understood. The protective effects of this dietary pattern may depend on its action towards CVD risk factors, such as abdominal obesity, lipids levels, glucose metabolism, and blood pressure levels (Grosso et al., 2014c; Grosso et al., 2014d). Among direct action on cardiovascular system, observational and experimental studies reported that adherence to the Mediterranean diet has been associated not only with a reduction in endothelial function but also with improvement in inflammatory status (Schwingshackl and Hoffmann 2014). Furthermore, adhering to a Mediterranean dietary pattern may also provide better cardiac autonomic function, independently of genetic or lifestyle factors other than diet (Dai et al., 2010). Similar benefits have been found also in patients with a previous episode of CVD, in whom Mediterranean diet adherence provided preservation of left ventricular systolic function (Chrysohoou et al., 2010). General components of the diet that seems to play a major role in cardiovascular health are: (i) fiber, especially from fruit and vegetables; (ii) whole grains and legumes (Satija and $\mathrm{Hu} 2012$ ); (iii) an favorable fatty acids ratio, with special regard to omega-3 PUFA (Christensen et al., 2005; Park et al., 2009), in particular $\alpha$-linolenic acid (ALA) from vegetal origin (de Lorgeril and Salen 2004); and (iv) docosahexaenoic acid (DHA) and eicosapentaenoic acid (EPA) from fish (Mozaffarian and Wu 2012; Marventano et al., 2015). Other nutrients with anti-inflammatory properties, such as vitamins and phenolic compounds from fruit and vegetables, may lead to better functionality and ameliorate inflammation and oxidative stress in case of infarction, limit infarct size and improve ventricular remodeling process (Nadtochiy and Redman 2011), which are all major determinants of post-infarction survival and prognosis (Zamora-Ros et al., 2013; Tresserra-Rimbau et al., 2014).

Adherence to the Mediterranean diet has been evaluated by using scoring systems in previous studies. While different systems all included main features of this dietary pattern, slight differences are seen on classification of food groups, for example, nuts and fish as independent components, and definition of amount to be considered highly adherent, such as frequency of consumption versus portion size. This nonconformity in the interpretation of Mediterranean diet has to be considered when comparing results across studies, especially when conducted in different countries with significantly different dietary habits. A recent meta-analysis (Sofi et al., 2013) proposed a Mediterranean diet adherence score system by using literature-based cut-off points. In comparison, our calculation of food amount consumed by individuals highly adherent to the diet did not differ substantially for components such as fruit, vegetables, alcohol and cereals. However, in our analysis consumption of fish (roughly more than $30 \mathrm{~g} / \mathrm{d}$ ) and legumes $(20 \mathrm{~g} / \mathrm{d})$ among individuals highly adherent to Mediterranean diet was less than suggested by previously published analysis (more than $100 \mathrm{~g} / \mathrm{d}$ and $70 \mathrm{~g} / \mathrm{d}$, respectively), while their CVD-protective effect was significant for legumes and near significant for fish intake. While no significant risk was associated with dairy products in previous review (Soedamah-Muthu et al., 2011), our analysis resulted in increased CVD risk associated with dairy consumption.

The role of olive oil (Martínez-González et al., 2014), fruit and vegetables (Wang et al., 2014), and legumes and nuts (Afshin et al., 2014; Grosso et al, 2015) on CVD outcomes have been extensively reported. While the effects of specific food categories may be attenuated due to synergic effect of the overall diet, the significant inverse associations with CVD outcomes suggest the individual role of specific Mediterranean diet components in determining disease risk outcomes. Therefore, when evaluating point increase in adherence of the Mediterranean diet, the evaluation should be accompanied by analysis of individual component effects. While adherence to the Mediterranean diet was considered as a whole in the GOSPEL study (Giannuzzi et al., 2008), the characterization of this dietary pattern has been proposed to rely on some specific key factors in other RCTs examined in this meta-analysis. For instance, a diet rich in ALA in the Lyon Diet Heart Study (de Lorgeril et al., 1999); consumption of fruit, vegetables, and nuts in the IndoMediterranean Diet Heart Study (Singh et al., 2002); and consumption of extra-virgin olive oil and nuts in the PREDIMED study (Estruch and Salas-Salvado 2013). The identification of the key components is important since differences in the definition of a Mediterranean-type diet among studies are generally relevant. In the Lyon Diet Heart Study, patients did not accept olive oil as the only source of fat and ALA was supplied by a rapeseed (canola) oil-based margarine consumption (de Lorgeril et al., 1999). As well, in the Indo-Mediterranean Diet Heart Study, olive oil was never mentioned and was not considered part of the diet. In contrast, one arm of the PREDIMED study focused on extravirgin olive oil consumption (Estruch et al., 2013). Moreover, nut consumption was emphasized in the Indo-Mediterranean Diet Heart Study and the PREDIMED study while less considered in other RCTs. Differences between prospective 
and experimental studies emerged when we examined specific components of the diet. For example, olive oil had far more effective results in reducing CVD risk than other Mediterranean diet components in prospective studies, but not particularly in RCTs with the exception of the PREDIMED study (Estruch and Salas-Salvado 2013). Moreover, it is not clear whether the main sources of ALA should be margarine or nuts. Pooled analysis of prospective studies further suggested that the phytochemicals and antioxidants content of fruits and vegetables could alone play a major role in the observed benefits of the Mediterranean diet. Although the benefits of the overall dietary pattern can be considered as exerted from a holistic point of view due to a likely synergic effect of all its components, future RCTs should also assess the role of specific components, as according to our results the classic approach to randomly consider any of this diet characteristics as equivalent in decreasing the risk of CVD may not be entirely appropriate.

Certain limitations of this study should be mentioned. To begin with, food categories included in the Mediterranean dietary pattern are not homogeneous among scores and methods used to assess the diet may vary across different studies. For instance, only two studies (Fung et al., 2009; Hoevenaar-Blom et al., 2012) included nut consumption separately whereas in other studies (Knoops et al., 2004; Mitrou et al., 2007; Buckland et al., 2009; Buckland et al., 2011; Martinez-Gonzalez et al., 2011) nuts were included with fruit and legumes consumption. Some other studies did not included legumes (Buckland et al., 2011; Tognon et al., 2012; Tognon et al., 2013) and one study used frequency of weekly consumption by portion rather than daily amount by weight (Fung et al., 2009). Although the basic diet characteristics were present in all of the included epidemiological studies, the differences in diet adherence assessment, mostly due to lack of specific food group components, may underestimate the effects on CVD protection. Another limitation is the non-conformity of exposure categories included in the meta-analysis (the use of different methodologies to group individuals according to exposure categories). However, despite these variations in exposure assessment, this approach is widely used in literature and we observed similar results across studies and no evidence of significant heterogeneity.

The findings of the present meta-analysis confirm that high adherence to the Mediterranean dietary pattern is associated with lower risk of CVD incidence and mortality, but the effects on specific cardiovascular outcomes between prospective studies and RCTs varies. Results from RCTs are limited due to scarce number of studies and warrants further investigations to better quantify the effectiveness of Mediterranean diet adherence especially in high-risk groups (secondary prevention). Among the single components of the diet, olive oil, vegetable, fruit, and legumes seem to provide the strongest cardio-protective properties and should be considered as crucial in the definition of future RCTs to effectively evaluate their effects.

\section{Acknowledgements}

Author contributions were the following: GG conceived and designed the study; GG, SM, AM analyzed data; GG, JY, SNK wrote the paper; GG, SM, FG, LS and SNK interpreted results; GG, JY, LS, AP, FG and SNK revised the article for important intellectual content. All authors approved the final version of the article.

\section{References}

Afshin, A., Micha, R., Khatibzadeh, S. and Mozaffarian, D. (2014). Consumption of nuts and legumes and risk of incident ischemic heart disease, stroke, and diabetes: a systematic review and meta-analysis. Am. J. Clin. Nutr. 100: 278-288.

Agnoli, C., Krogh, V., Grioni, S., Sieri, S., Palli, D., Masala, G., Sacerdote, C., Vineis, P., Tumino, R., Frasca, G., Pala, V., Berrino, F., Chiodini, P., Mattiello, A. and Panico, S. (2011). A priori-defined dietary patterns are associated with reduced risk of stroke in a large Italian cohort. J. Nutr. 141: 1552-1558.

Bach, A., Serra-Majem, L., Carrasco, J. L., Roman, B., Ngo, J., Bertomeu, I. and Obrador, B. (2006). The use of indexes evaluating the adherence to the Mediterranean diet in epidemiological studies: a review. Public Health Nutr. 9: 132-146.

Bertoia, M. L., Triche, E. W., Michaud, D. S., Baylin, A., Hogan, J. W., Neuhouser, M. L., Tinker, L. F., Van Horn, L., Waring, M. E., Li, W., Shikany, J. M. and Eaton, C. B. (2014). Mediterranean and Dietary Approaches to Stop Hypertension dietary patterns and risk of sudden cardiac death in postmenopausal women. Am. J. Clin. Nutr. 99: 344-351.

Buckland, G., Agudo, A., Travier, N., Huerta, J. M., Cirera, L., Tormo, M. J., Navarro, C., Chirlaque, M. D., Moreno-Iribas, C., Ardanaz, E., Barricarte, A., Etxeberria, J., Marin, P., Quiros, J. R., Redondo, M. L., Larranaga, N., Amiano, P., Dorronsoro, M., Arriola, L., Basterretxea, M., Sanchez, M. J., Molina, E. and Gonzalez, C. A. (2011). Adherence to the Mediterranean diet reduces mortality in the Spanish cohort of the European Prospective Investigation into Cancer and Nutrition (EPICSpain). Br. J. Nutr. 106: 1581-1591.

Buckland, G., Gonzalez, C. A., Agudo, A., Vilardell, M., Berenguer, A., Amiano, P., Ardanaz, E., Arriola, L., Barricarte, A., Basterretxea, M., Chirlaque, M. D., Cirera, L., Dorronsoro, M., Egues, N., Huerta, J. M., Larranaga, N., Marin, P., Martinez, C., Molina, E., Navarro, C., Quiros, J. R., Rodriguez, L., Sanchez, M. J., Tormo, M. J. and MorenoIribas, C. (2009). Adherence to the Mediterranean diet and risk of coronary heart disease in the Spanish EPIC Cohort Study. Am. J. Epidemiol. 170: $1518-1529$.

Buscemi, S., Nicolucci, A., Mattina, A., Rosafio, G., Massenti, F. M., Lucisano, G., Galvano, F., Amodio, E., Pellegrini, F., Barile, A. M., Maniaci, V., Grosso, G., Verga, S., Sprini, D. and Rini, G. B. (2013). Association of dietary patterns with insulin resistance and clinically silent carotid atherosclerosis in apparently healthy people. Eur. J. Clin. Nutr. 67: 1284-1290.

Capewell, S. and Buchan, I. (2012). Why have sustained increases in obesity and type 2 diabetes not offset declines in cardiovascular mortality over recent decades in Western countries? Nutr. Metab. Cardiovasc. Dis. 22: 307-311.

Christensen, J. H., Schmidt, E. B., Molenberg, D. and Toft, E. (2005). Alpha-linolenic acid and heart rate variability in women examined for coronary artery disease. Nutr. Metab. Cardiovasc. Dis. 15: 345351. 
Chrysohoou, C., Panagiotakos, D. B., Aggelopoulos, P., Kastorini, C. M., Kehagia, I., Pitsavos, C. and Stefanadis, C. (2010). The Mediterranean diet contributes to the preservation of left ventricular systolic function and to the long-term favorable prognosis of patients who have had an acute coronary event. Am. J. Clin. Nutr. 92: 47-54.

Dai, J., Lampert, R., Wilson, P. W., Goldberg, J., Ziegler, T. R. and Vaccarino, V. (2010). Mediterranean dietary pattern is associated with improved cardiac autonomic function among middle-aged men: a twin study. Circ. Cardiovasc. Qual. Outcomes 3: 366-373.

de Lorgeril, M. and Salen, P. (2004). Alpha-linolenic acid and coronary heart disease. Nutr. Metab. Cardiovasc. Dis. 14: 162-169.

de Lorgeril, M., Salen, P., Martin, J. L., Monjaud, I., Delaye, J. and Mamelle, N. (1999). Mediterranean diet, traditional risk factors, and the rate of cardiovascular complications after myocardial infarction: final report of the Lyon Diet Heart Study. Circulation 99: 779-785.

Dilis, V., Katsoulis, M., Lagiou, P., Trichopoulos, D., Naska, A. and Trichopoulou, A. (2012). Mediterranean diet and CHD: the Greek European Prospective Investigation into Cancer and Nutrition cohort. $\mathrm{Br}$. J. Nutr. 108: 699-709.

Estruch, R., Ros, E., Salas-Salvado, J., Covas, M. I., Corella, D., Aros, F., Gomez-Gracia, E., Ruiz-Gutierrez, V., Fiol, M., Lapetra, J., Lamuela-Raventos, R. M., Serra-Majem, L., Pinto, X., Basora, J., Munoz, M. A., Sorli, J. V., Martinez, J. A. and MartinezGonzalez, M. A. (2013). Primary prevention of cardiovascular disease with a Mediterranean diet. N. Engl. J. Med. 368: 1279-1290.

Estruch, R. and Salas-Salvado, J. (2013). "Towards an even healthier Mediterranean diet". Nutr. Metab. Cardiovasc. Dis. 23: 1163-1166.

Fung, T. T., Rexrode, K. M., Mantzoros, C. S., Manson, J. E., Willett, W. C. and Hu, F. B. (2009). Mediterranean diet and incidence of and mortality from coronary heart disease and stroke in women. Circulation 119: 1093-1100.

Gardener, H., Wright, C. B., Gu, Y., Demmer, R. T., BodenAlbala, B., Elkind, M. S., Sacco, R. L. and Scarmeas, N. (2011). Mediterranean-style diet and risk of ischemic stroke, myocardial infarction, and vascular death: the Northern Manhattan Study. Am. J. Clin. Nutr. 94: 1458-1464.

Giannuzzi, P., Temporelli, P. L., Marchioli, R., Maggioni, A. P., Balestroni, G., Ceci, V., Chieffo, C., Gattone, M., Griffo, R., Schweiger, C., Tavazzi, L., Urbinati, S., Valagussa, F., Vanuzzo, D. and Investigators, G. (2008). Global secondary prevention strategies to limit event recurrence after myocardial infarction: results of the GOSPEL study, a multicenter, randomized controlled trial from the Italian Cardiac Rehabilitation Network. Arch. Intern. Med. 168: 2194-2204.

Grosso, G., Marventano, S., Galvano, F., Pajak, A. and Mistretta, A. (2014a). Factors Associated With Metabolic Syndrome in a Mediterranean Population: Role of Caffeinated Beverages. $J$. Epidemiol. 24: 327-33

Grosso, G., Pajak, A., Mistretta, A., Marventano, S., Raciti, T., Buscemi, S., Drago, F., Scalfi, L. and Galvano, F. (2014b). Protective role of the Mediterranean diet on several cardiovascular risk factors: evidence from Sicily, southern Italy. Nutr. Metab. Cardiovasc. Dis. 24: 370-377.

Grosso, G., Mistretta, A., Frigiola, A., Gruttadauria, S., Biondi, A., Basile, F., Vitaglione, P., D'Orazio, N. and Galvano, F. (2014c). Mediterranean diet and cardiovascular risk factors: a systematic review. Crit. Rev. Food Sci. Nutr. 54: 593-610.

Grosso, G., Mistretta, A., Marventano, S., Purrello, A., Vitaglione, P., Calabrese, G., Drago, F., Galvano, F. (2014d). Beneficial effects of the Mediterranean diet on metabolic syndrome. Curr. Pharm. Des. 20: 5039-5044.

Grosso, G., Yang, J., Marventano, S., Micek, A., Galvano, F., Kales, S. N. (2015). Nut consumption on all-cause, cardiovascular, and cancer mortality risk: a systematic review and meta-analysis of epidemiologic studies. Am. J. Clin. Nutr. 101: 78393.

Hodge, A. M., English, D. R., Itsiopoulos, C., O'Dea, K. and Giles, G. G. (2011). Does a Mediterranean diet reduce the mortality risk associated with diabetes: evidence from the Melbourne Collaborative Cohort Study. Nutr. Metab. Cardiovasc. Dis. 21: 733-739.

Hoevenaar-Blom, M. P., Nooyens, A. C., Kromhout, D., Spijkerman, A. M., Beulens, J. W., van der Schouw, Y. T., Bueno-de-Mesquita, B. and Verschuren, W. M. (2012). Mediterranean style diet and 12-year incidence of cardiovascular diseases: the EPIC-NL cohort study. PLoS One 7: e45458.

Hoevenaar-Blom, M. P., Spijkerman, A. M., Boshuizen, H. C., Boer, J. M., Kromhout, D. and Verschuren, W. M. (2013). Effect of using repeated measurements of a Mediterranean style diet on the strength of the association with cardiovascular disease during 12 years: the Doetinchem Cohort Study. Eur. J. Nutr. 53: $1209-1215$

Jadad, A. R., Moore, R. A., Carroll, D., Jenkinson, C., Reynolds, D. J., Gavaghan, D. J. and McQuay, H. J. (1996). Assessing the quality of reports of randomized clinical trials: is blinding necessary? Control. Clin. Trials 17: 1-12.

Kastorini, C. M., Milionis, H. J., Goudevenos, J. A. and Panagiotakos, D. B. (2010). Mediterranean diet and coronary heart disease: is obesity a link? - A systematic review. Nutr. Metab. Cardiovasc. Dis. 20: $536-551$.

Knoops, K. T., de Groot, L. C., Kromhout, D., Perrin, A. E., Moreiras-Varela, O., Menotti, A. and van Staveren, W. A. (2004). Mediterranean diet, lifestyle factors, and 10-year mortality in elderly European men and women: the HALE project. JAMA 292: 1433-1439.

Lopez-Garcia, E., Rodriguez-Artalejo, F., Li, T. Y., Fung, T. T., Li, S., Willett, W. C., Rimm, E. B. and Hu, F. B. (2014). The Mediterranean-style dietary pattern and mortality among men and women with cardiovascular disease. Am. J. Clin. Nutr. 99: 172180.

Martínez-González, M. A., Dominguez, L. J. and DelgadoRodríguez, M. (2014). Olive oil consumption and risk of CHD and/or stroke: a meta-analysis of casecontrol, cohort and intervention studies. Br. J. Nutr. 112: $248-259$

Martinez-Gonzalez, M. A., Garcia-Lopez, M., Bes-Rastrollo, M., Toledo, E., Martinez-Lapiscina, E. H., Delgado-Rodriguez, M., Vazquez, Z., Benito, S. 
and Beunza, J. J. (2011). Mediterranean diet and the incidence of cardiovascular disease: a Spanish cohort. Nutr. Metab. Cardiovasc. Dis. 21: 237-244.

Marventano, S., Kolacz, P., Castellano, S., Galvano, F., Buscemi, S., Mistretta, A., Grosso, G. (2015). A review of recent evidence in human studies of n-3 and n-6 PUFA intake on cardiovascular disease, cancer, and depressive disorders: does the ratio really matter? Int. J. Food Sci. Nutr. 66: 611-22.

Menotti, A., Alberti-Fidanza, A. and Fidanza, F. (2012). The association of the Mediterranean Adequacy Index with fatal coronary events in an Italian middle-aged male population followed for 40 years. Nutr. Metab. Cardiovasc. Dis. 22: 369-375.

Mente, A., de Koning, L., Shannon, H. S. and Anand, S. S. (2009). A systematic review of the evidence supporting a causal link between dietary factors and coronary heart disease. Arch Intern. Med. 169: 659669.

Misirli, G., Benetou, V., Lagiou, P., Bamia, C., Trichopoulos, D. and Trichopoulou, A. (2012). Relation of the traditional Mediterranean diet to cerebrovascular disease in a Mediterranean population. Am. J. Epidemiol. 176: 1185-1192.

Mitrou, P. N., Kipnis, V., Thiebaut, A. C., Reedy, J., Subar, A. F., Wirfalt, E., Flood, A., Mouw, T., Hollenbeck, A. R., Leitzmann, M. F. and Schatzkin, A. (2007). Mediterranean dietary pattern and prediction of all-cause mortality in a US population: results from the NIH-AARP Diet and Health Study. Arch. Intern. Med. 167: 2461-2468.

Mozaffarian, D. and Wu, J. H. (2012). (n-3) fatty acids and cardiovascular health: are effects of EPA and DHA shared or complementary? J. Nutr. 142: 614S$625 \mathrm{~S}$.

Nadtochiy, S. M. and Redman, E. K. (2011). Mediterranean diet and cardioprotection: the role of nitrite, polyunsaturated fatty acids, and polyphenols. Nutrition 27: 733-744.

Panagiotakos, D. B., Pitsavos, C., Chrysohoou, C., Skoumas, I. and Stefanadis, C. (2008). Five-year incidence of cardiovascular disease and its predictors in Greece: the ATTICA study. Vasc. Med. 13: 113-121.

Park, S. K., Tucker, K. L., O'Neill, M. S., Sparrow, D., Vokonas, P. S., Hu, H. and Schwartz, J. (2009). Fruit, vegetable, and fish consumption and heart rate variability: the Veterans Administration Normative Aging Study. Am. J. Clin. Nutr. 89: 778786.

Satija, A. and Hu, F. B. (2012). Cardiovascular benefits of dietary fiber. Curr. Atheroscler. Rep. 14: 505-514.

Schwingshackl, L. and Hoffmann, G. (2014). Mediterranean dietary pattern, inflammation and endothelial function: a systematic review and meta-analysis of intervention trials. Nutr. Metab. Cardiovasc. Dis. 24: 929-939.

Singh, R. B., Dubnov, G., Niaz, M. A., Ghosh, S., Singh, R., Rastogi, S. S., Manor, O., Pella, D. and Berry, E. M. (2002). Effect of an Indo-Mediterranean diet on progression of coronary artery disease in high risk patients (Indo-Mediterranean Diet Heart Study): a randomised single-blind trial. Lancet 360: 14551461.

Soedamah-Muthu, S. S., Ding, E. L., Al-Delaimy, W. K., Hu, F. B., Engberink, M. F., Willett, W. C. and Geleijnse, J. M. (2011). Milk and dairy consumption and incidence of cardiovascular diseases and all-cause mortality: dose-response meta-analysis of prospective cohort studies. Am. J. Clin. Nutr. 93: 158-171.

Sofi, F., Macchi, C., Abbate, R., Gensini, G. F. and Casini, A. (2013). Mediterranean diet and health status: an updated meta-analysis and a proposal for a literature-based adherence score. Public Health Nutr. 1-14.

Tognon, G., Lissner, L., Saebye, D., Walker, K. Z. and Heitmann, B. L. (2013). The Mediterranean diet in relation to mortality and CVD: a Danish cohort study. Br. J. Nutr. 111: 151-159.

Tognon, G., Nilsson, L. M., Lissner, L., Johansson, I., Hallmans, G., Lindahl, B. and Winkvist, A. (2012). The Mediterranean diet score and mortality are inversely associated in adults living in the subarctic region. J. Nutr. 142: 1547-1553.

Tresserra-Rimbau, A., Rimm, E. B., Medina-Remon, A., Martinez-Gonzalez, M. A., de la Torre, R., Corella, D., Salas-Salvado, J., Gomez-Gracia, E., Lapetra, J., Aros, F., Fiol, M., Ros, E., Serra-Majem, L., Pinto, X., Saez, G. T., Basora, J., Sorli, J. V., Martinez, J. A., Vinyoles, E., Ruiz-Gutierrez, V., Estruch, R. and Lamuela-Raventos, R. M. (2014). Inverse association between habitual polyphenol intake and incidence of cardiovascular events in the PREDIMED study. Nutr. Metab. Cardiovasc. Dis. 24: 639-647.

Wang, X., Ouyang, Y., Liu, J., Zhu, M., Zhao, G., Bao, W. and $\mathrm{Hu}, \mathrm{F}$. B. (2014). Fruit and vegetable consumption and mortality from all causes, cardiovascular disease, and cancer: systematic review and dose-response meta-analysis of prospective cohort studies. BMJ 29: 349:g4490.

Wells, G. A., Shea, B., O'Connell, D., Peterson, J., Welch, V., Losos, M. and Tugwell, P. (1999) The Newcastle-Ottawa Scale (NOS) for assessing the quality of nonrandomised studies in meta-analyses. Ottawa Health Research Institute.

Yang, J., Farioli, A., Korre, M. and Kales, S. N. (2014). Modified mediterranean diet score and cardiovascular risk in a North American working population. PLoS One 9: e87539.

Zamora-Ros, R., Serafini, M., Estruch, R., LamuelaRaventos, R. M., Martinez-Gonzalez, M. A., SalasSalvado, J., Fiol, M., Lapetra, J., Aros, F., Covas, M. I. and Andres-Lacueva, C. (2013). Mediterranean diet and non enzymatic antioxidant capacity in the PREDIMED study: evidence for a mechanism of antioxidant tuning. Nutr. Metab. Cardiovasc. Dis. 23: 1167-1174. 
Table 1. Main characteristics of prospective studies exploring the relation between Mediterranean diet adherence and cardiovascular disease (CVD) incidence and mortality.

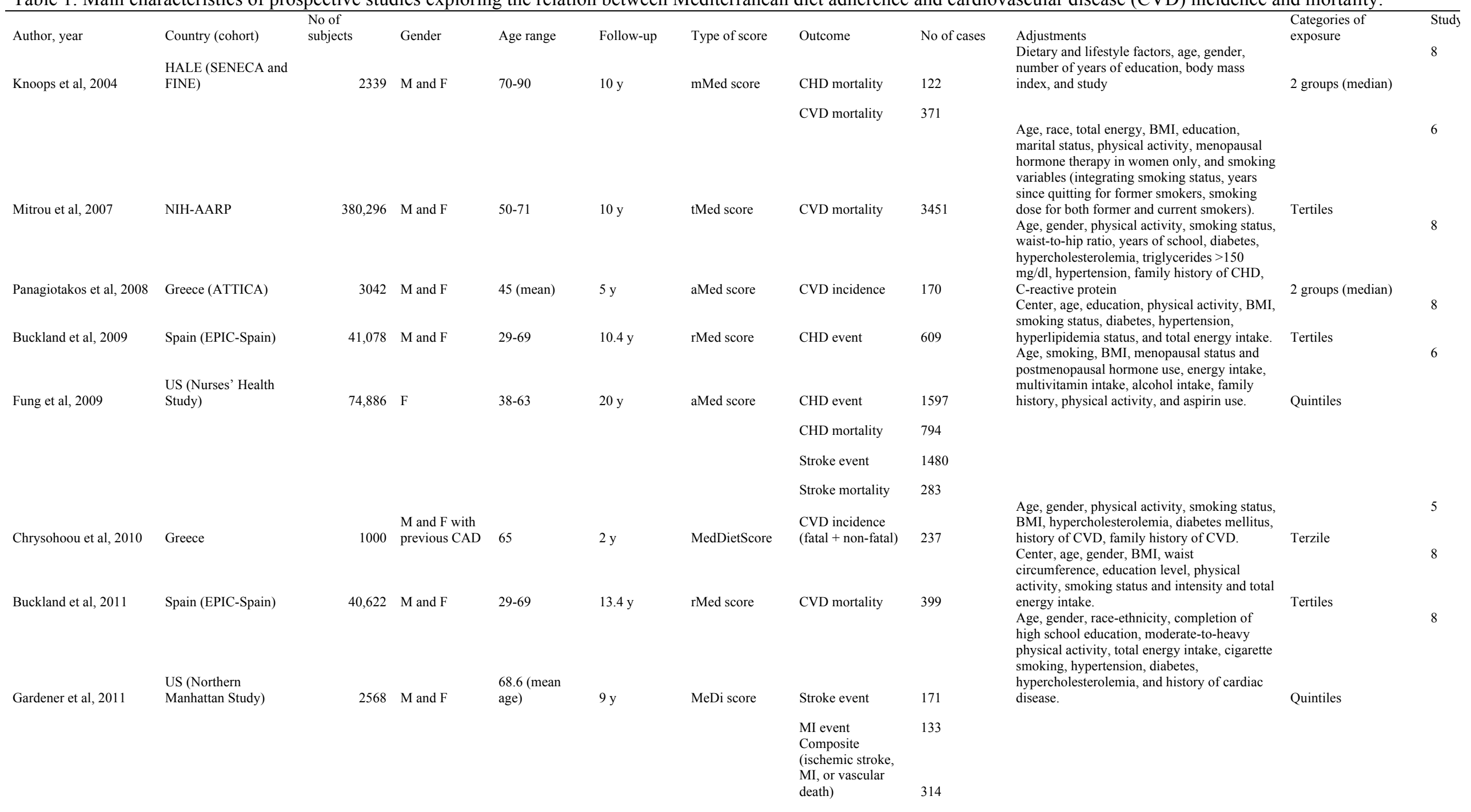




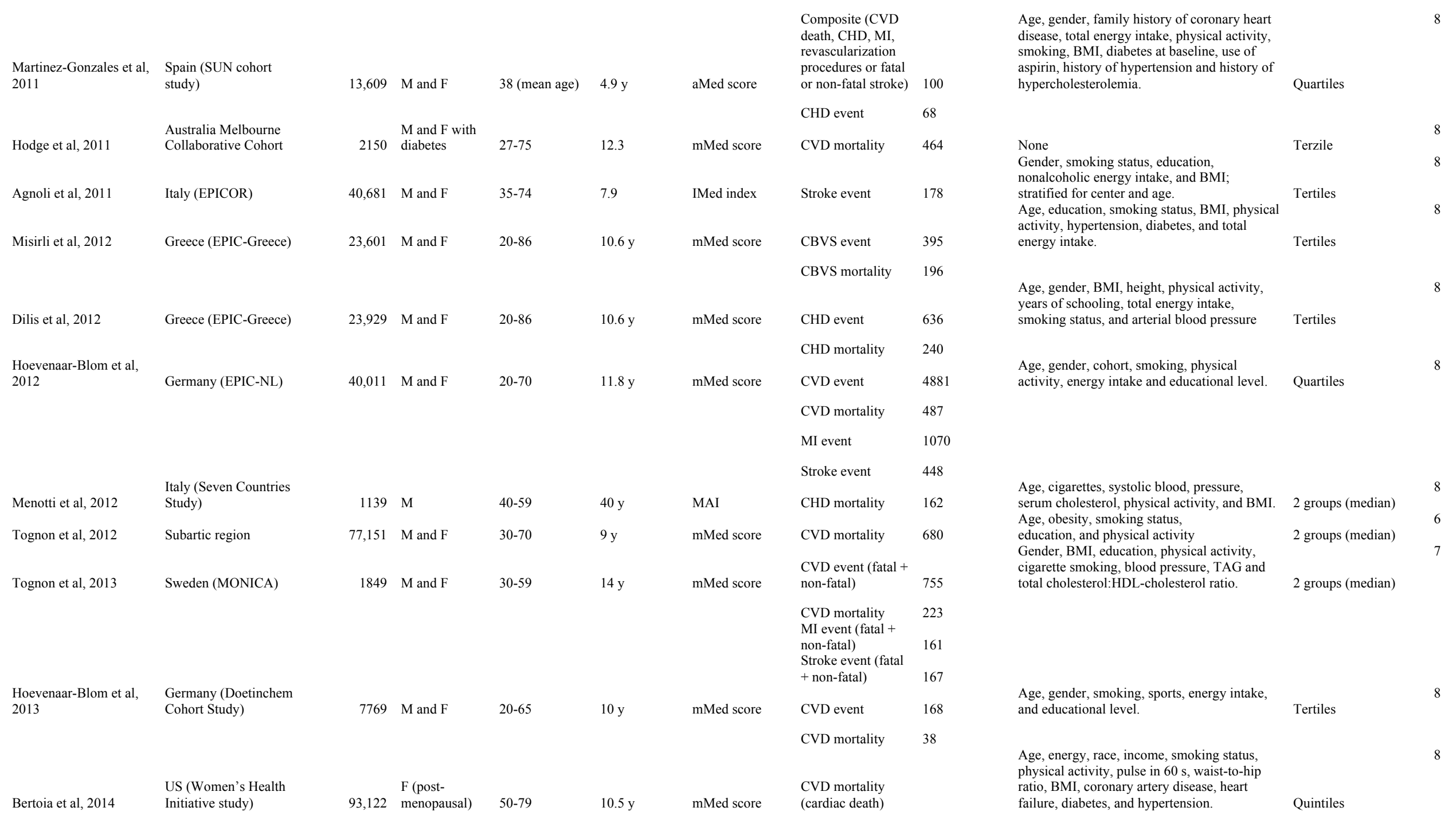




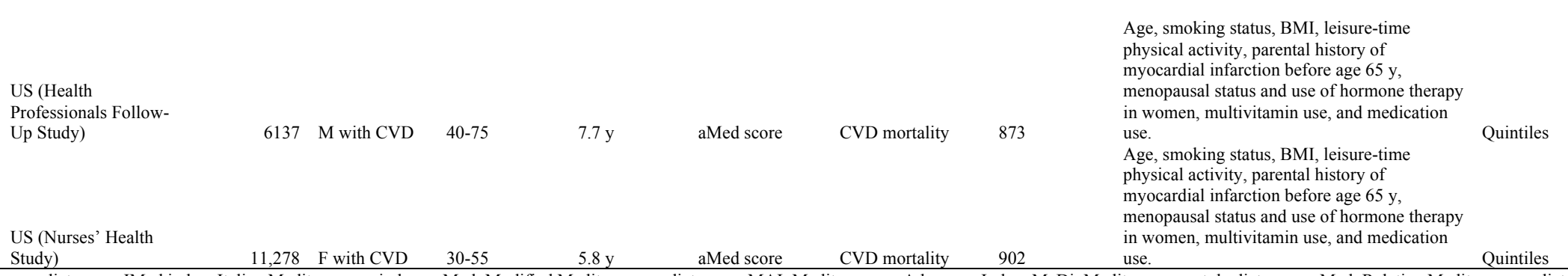

Lopez-Garcia et al, 2014 Professionals Follo

\begin{tabular}{l} 
US (Nurses' Health \\
Study) \\
\hline aMed, Alternate Mediterranean diet score; IMed \\
tMed, Traditional Mediterranean diet score.
\end{tabular}

$\begin{array}{lll}5.8 \mathrm{y} & \text { aMed score } & \text { CVD mortality } \\ 902\end{array}$ 
DOI: $10.1080 / 10408398.2015 .1107021$

Table 2. Subgroup analyses for composite CVD incidence and mortality.

\begin{tabular}{lccc}
\hline & Number of studies & $\mathrm{RR}(95 \% \mathrm{CI})$ & Heterogeneity $\left(\mathrm{I}^{2}\right)$ \\
\hline Geographical area & & & \\
$\quad$ Mediterranean & 9 & $0.55(0.44,0.71)$ & $72 \%$ \\
$\quad$ Non-Mediterranean & 11 & $0.77(0.70,0.83)$ & $74 \%$ \\
$\begin{array}{l}\text { Sample size } \\
\leq 10,000\end{array}$ & 10 & $0.72(0.62,0.83)$ & $83 \%$ \\
$>10,000$ & 10 & $0.71(0.65,0.77)$ & $42 \%$ \\
$\begin{array}{l}\text { Duration of follow-up } \\
\leq 10 \text { years }\end{array}$ & 12 & $0.74(0.67,0.81)$ & $79 \%$ \\
$>10$ years & 8 & $0.66(0.55,0.79)$ & $68 \%$ \\
Type of adherence score & & & $75 \%$ \\
mMed Diet & 9 & $0.77(0.69,0.85)$ & $70 \%$ \\
$\quad$ Others & 11 & $0.65(0.57,0.75)$ & \\
\hline
\end{tabular}


Table 3. Cut-off points of individual components of Mediterranean diet in participants in the highest category of exposure (highest adherence). Values should be intended as lower cut-off for foods considered beneficial according to the Mediterranean diet (i.e., fruit, vegetable, olive oil, alcohol, fish, legumes, cereals, nuts), and upper cut-off for those considered detrimental (i.e., meat and dairy products).

\begin{tabular}{|c|c|c|c|c|c|c|c|c|c|c|}
\hline & Fruit & Vegetable & Olive oil & Alcohol & Fish & Legumes & Cereals & Meat & Dairy products & Nuts \\
\hline & \multicolumn{10}{|c|}{ g/day } \\
\hline Knoops et al, 2004 & 228 & 306 & - & - & 26 & $7^{\mathrm{a}}$ & 248 & 130 & 313 & - \\
\hline Buckland et al, 2009 & $366^{\mathrm{a}}$ & 270 & 24 & within range & 62 & 54 & 204 & 131 & 340 & - \\
\hline Fung et al, 2009 & 480 & 440 & - & 7 & 50 & 42 & 160 & 80 & - & 15 \\
\hline Buckland et al, 2011 & $380^{\mathrm{a}}$ & 282 & 25 & within range & 64 & - & 214 & 137 & 352 & - \\
\hline Gardener et al, 2011 & 131 & 67 & - & 0 & 10 & 9 & 61 & 33 & 92 & - \\
\hline Martinez-Gonzales et al, 2011 & $250^{\mathrm{a}}$ & 450 & & 35 & 86 & 21 & 85 & 174 & 162 & \\
\hline Misirli et al, 2012 & 350 & 520 & 50 & & 23 & 8 & 150 & 100 & 196 & - \\
\hline Dilis et al, 2012 & 209 & 231 & 23 & 19 & 17 & 7 & 70 & 54 & 147 & - \\
\hline Hoevenaar-Blom et al, 2012 & 155 & 113 & - & 8 & 8 & 13 & 194 & 110 & 371 & 6 \\
\hline Tognon et al, 2012 & 60 & 120 & - & 2 & 10 & - & 35 & 53 & 210 & - \\
\hline Tognon et al, 2013 & 109 & 192 & - & 16 & 25 & -- & 180 & 182 & 297 & - \\
\hline mean cut-off & 247 & 281 & 30 & 12 & 35 & 20 & 146 & 108 & 248 & 11 \\
\hline
\end{tabular}

${ }^{\mathrm{a}}$ Include nuts 
Table 4. Main characteristics of clinical randomized trials exploring the efficacy of Mediterranean diet on cardiovascular disease-related outcomes.

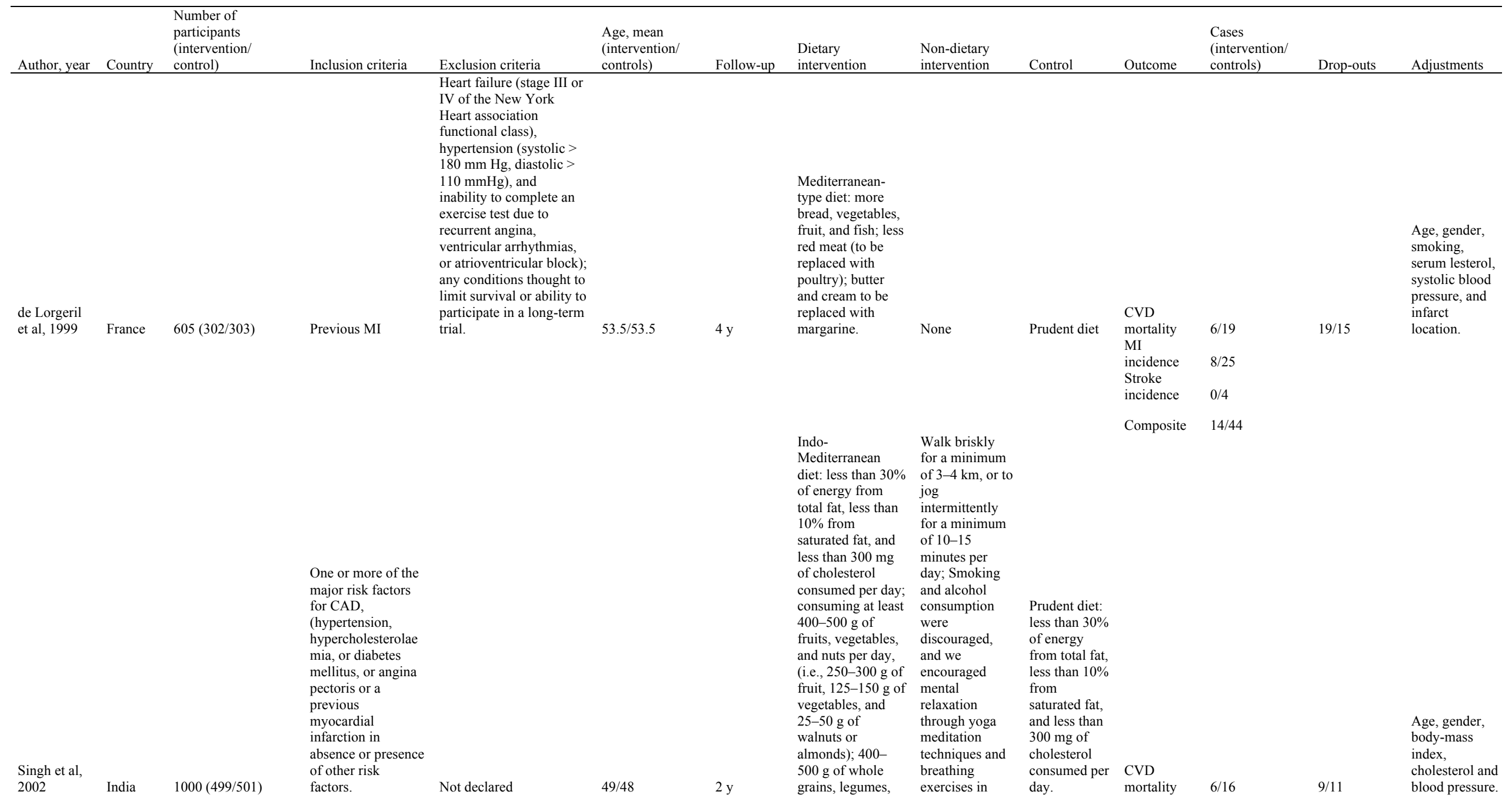




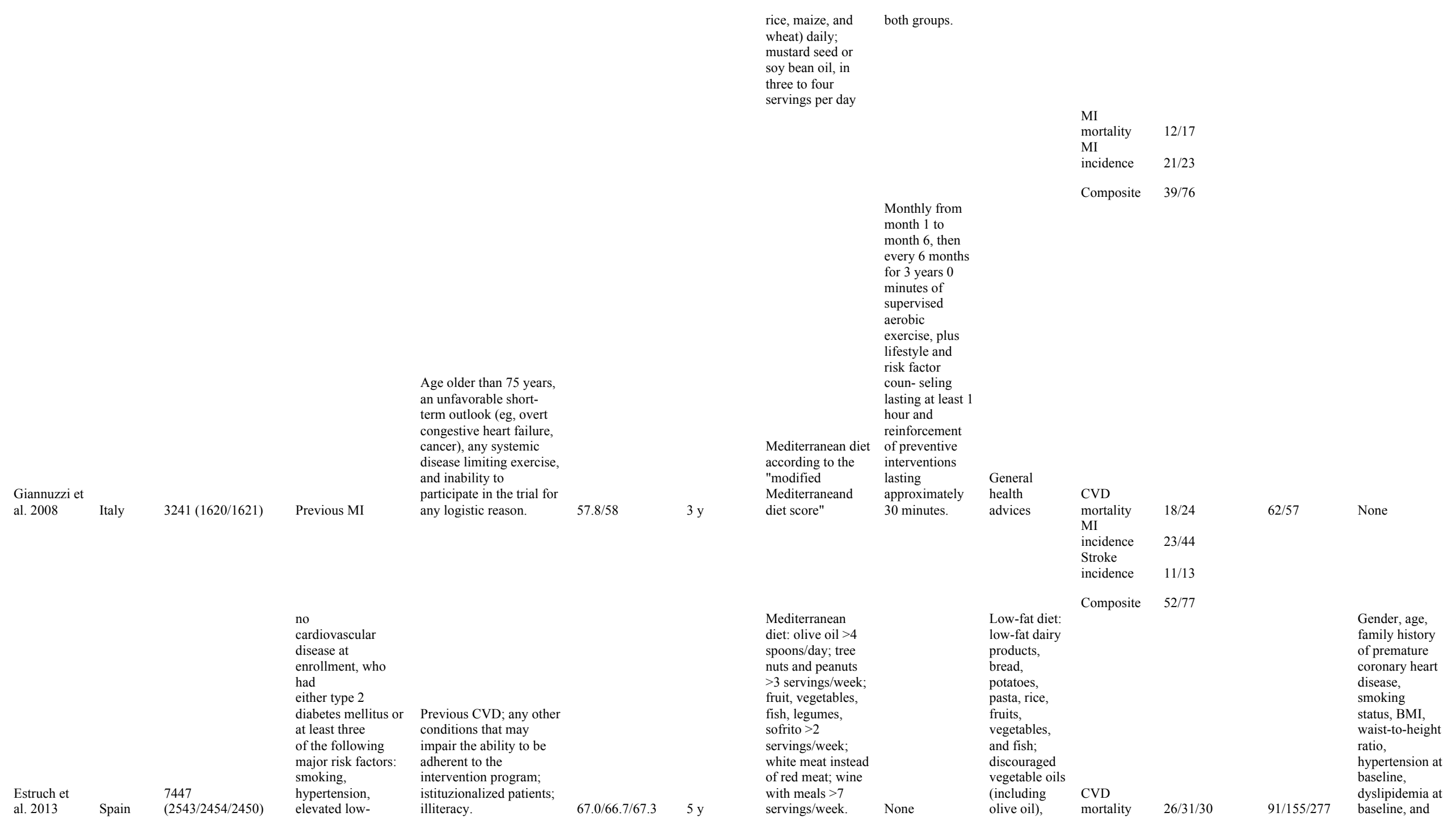


Grosso G et al, 2015 Nov (Epub ahead of print] PubMed PMID: 26528631

DOI: $10.1080 / 10408398.2015 .1107021$

density lipoprotein

cholesterol levels,

low high-density

lipoprotein

overweight or

overweight or

obesity, or a family
history of

history of

premature cor
heart disease. nuts.

diabetes at

baseline.

MI

incidenc

Stroke

ncidence

Composite 
Figure 1. Flowchart of publications included in this systematic review and meta-analysis.
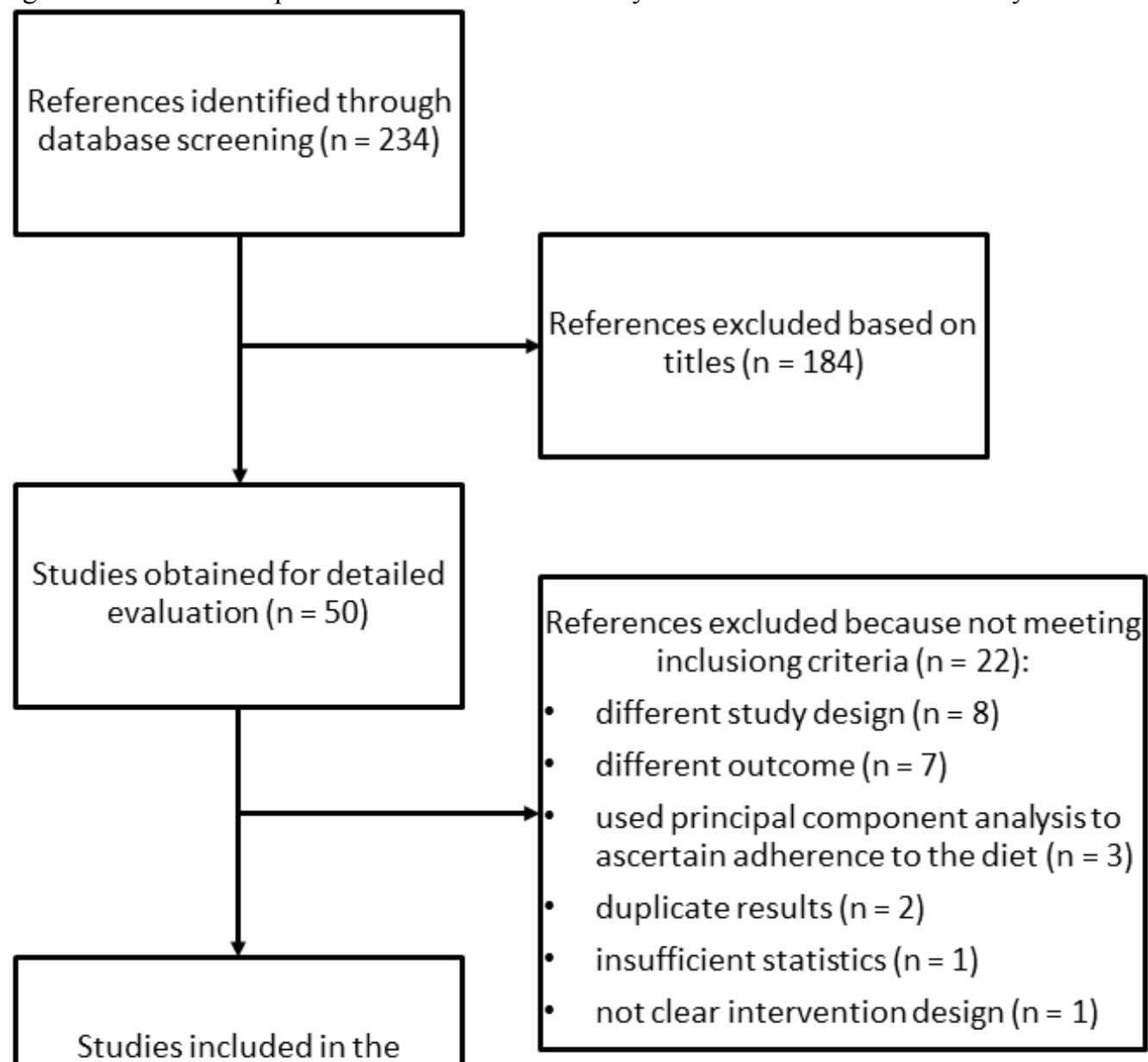
Sualitivincludedin the

Prospective studies included in the quantitative analysis

$$
(n=20)
$$

Case-control studies included in the quantitative analysis

$$
(n=4)
$$

Experimental studies (randomized controlled trials) included in the quantitative analysis $(n=4)$ 
Figure 2. Meta-analysis of prospective studies evaluating Mediterranean diet adherence and cardiovascular disease (CVD) risk by using relative risk (RR) and 95\% confidence intervals (CI) comparing highest diet adherence with the lowest category. Size of symbol is proportional to inverse of variance of RR; horizontal line represents $95 \% \mathrm{CI}$.

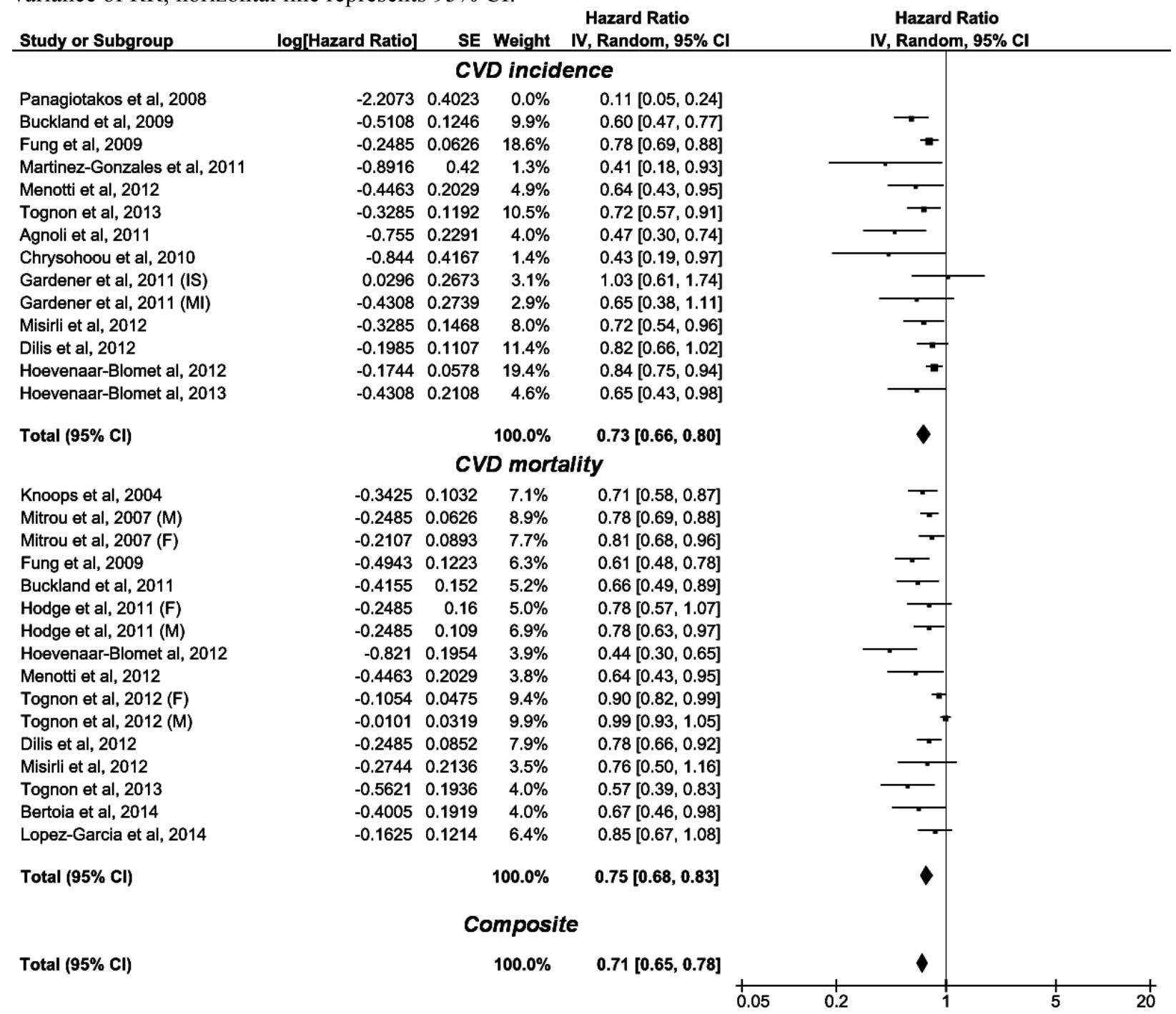


Figure 3. Meta-analysis of prospective studies evaluating Mediterranean diet adherence and coronary heart disease (CHD), myocardial infarction (MI), and stroke risk by using relative risk (RR) and 95\% confidence intervals (CI) comparing highest diet adherence with the lowest category. Size of symbol is proportional to inverse of variance of RR; horizontal line represents $95 \% \mathrm{CI}$.

Hazard Ratio

Study or Subgroup log[Hazard Ratio] SE Weight IV, Random, 95\% Cl

Buckland et al, 2009

Dilis et al, 2012

Fung et al, 2009

Martinez-Gonzales et al, 2011

Total $(95 \% \mathrm{Cl})$

Gardener et al, 2011

Hoevenaar-Blomet al, 2012

Tognon et al, 2013

Total $(95 \% \mathrm{Cl})$

Fung et al, 2009

Gardener et al, 2011

Agnoli et al, 2011

Hoevenaar-Blomet al, 2012

Tognon et al, 2013

Total $(95 \% \mathrm{Cl})$

\section{CHD incidence}

$\begin{array}{lll}-0.5108 & 0.1246 \quad 28.1 \%\end{array}$

$0.60[0.47,0.77]$

$\begin{array}{llll}-0.2485 & 0.093 & 36.9 \% & 0.78[0.65,0.94]\end{array}$

$\begin{array}{llll}-0.8675 & 0.4924 & 3.2 \% & 0.42[0.16,1.10]\end{array}$

$100.0 \% \quad 0.72[0.60,0.86]$

\section{MI incidence}

$\begin{array}{llll}-0.4308 & 0.2739 & 15.9 \% & 0.65[0.38,1.11]\end{array}$

$\left.\begin{array}{llll}-0.3567 & 0.1419 & 59.3 \% & 0.70[0.53,0.92\end{array}\right]$

$\begin{array}{llll}-0.462 & 0.2192 & 24.8 \% & 0.63[0.41,0.97]\end{array}$

$100.0 \% \quad 0.67[0.54,0.83]$

Stroke incidence

$\begin{array}{llll}-0.1054 & 0.093 & 32.5 \% & 0.90\end{array}[0.75,1.08]$

$\begin{array}{llll}0.0296 & 0.2673 & 13.6 \% & 1.03[0.61,1.74]\end{array}$

$\begin{array}{llll}-0.755 & 0.2291 & 16.5 \% & 0.47[0.30,0.74]\end{array}$

$\begin{array}{llll}-0.3567 & 0.2032 & 18.9 \% & 0.70\end{array}[0.47,1.04]$

$\begin{array}{llll}-0.2877 & 0.2069 & 18.5 \% & 0.75[0.50,1.13]\end{array}$

$100.0 \% \quad 0.76[0.60,0.96]$
Hazard Ratio

\author{
IV, Random, $95 \%$ CI
}

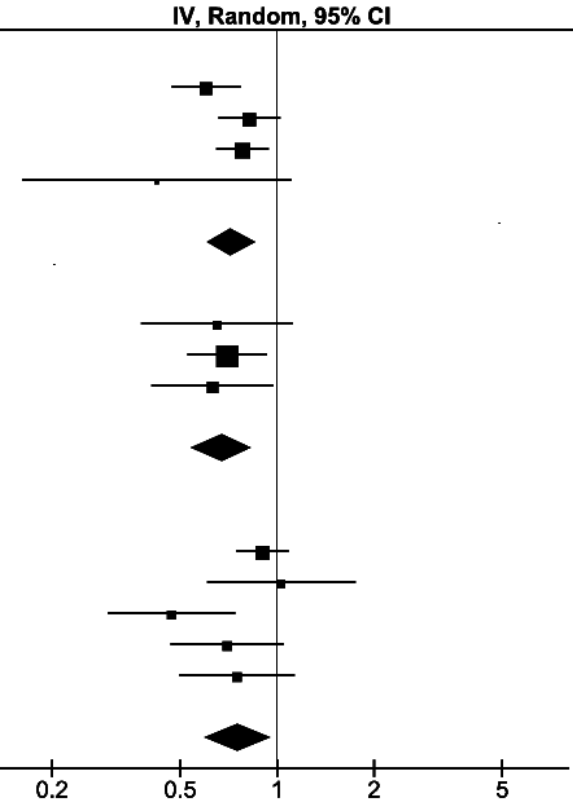


Figure 4. Pooled risk ratios of individual Mediterranean diet components and composite CVD outcomes.

Med diet

Component

Alcohol

Cereals

Dairy products

Fish

Fruit

Legumes

Meat

Olive oil

Vegetable
Risk Ratio Risk Ratio

IV, Random, $95 \% \mathrm{Cl}$

IV, Random, $95 \% \mathrm{Cl}$

$0.97[0.88,1.07]$

$0.95[0.90,1.00]$

$1.10[1.02,1.19]$

$0.96[0.91,1.01]$

$0.88[0.81,0.96]$

$0.90[0.83,0.98]$

$1.02[0.96,1.08]$

$0.83[0.77,0.89]$

$0.87[0.77,0.98]$

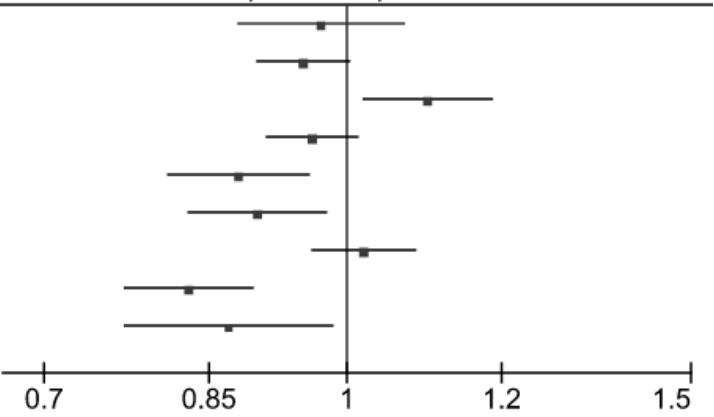


Figure 5. Meta-analysis of randomized controlled trials evaluating Mediterranean diet adherence and various cardiovascular outcomes by using relative risk (RR) and 95\% confidence intervals (CI). Size of symbol is proportional to inverse of variance of RR; horizontal line represents $95 \%$ CI.

Risk Ratio

Risk Ratio

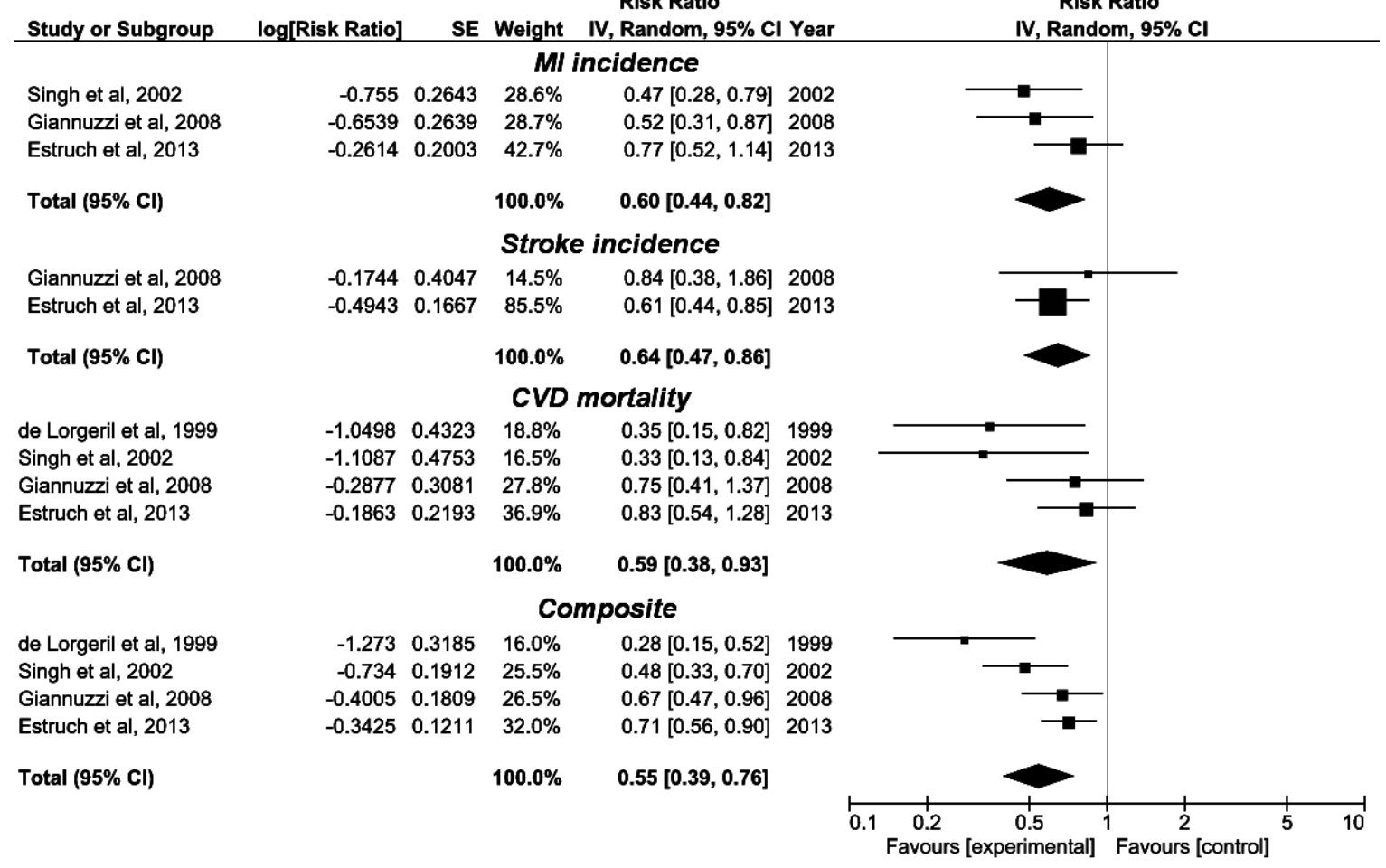


Supplemental Figure 1. Funnel plot of studies evaluating incidence of and mortality from cardiovascular disease.

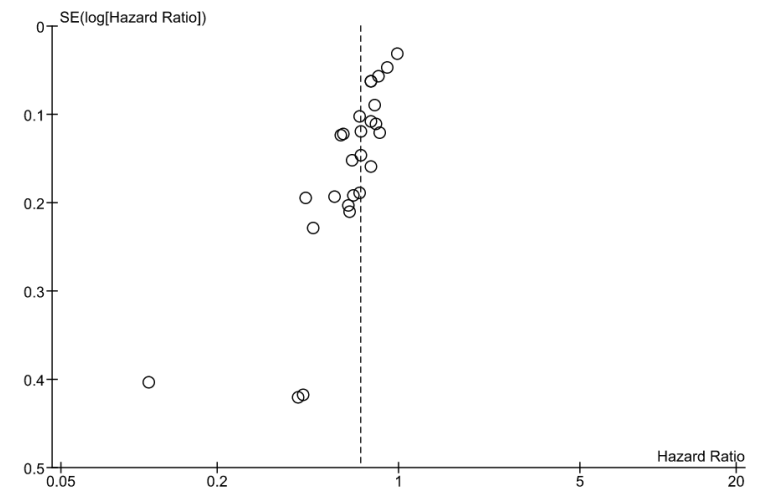

